\title{
Study on ecological awareness and performance of nursing personnel in dialysis units
}

\author{
Zyga Sofia*, Baroutsou Panagiota, Prezerakos Panagiotis, Lazakidou Athina, Rekliti Maria, Malliarou Maria \\ Assistant Professor, Nursing Department, University of Peloponnese, Sparta, Greece \\ $R N$, MSc, General Hospital of Sparta, Sparta, Greece \\ Assistant Professor, Nursing Department, University of Peloponnese, Sparta, Greece \\ Assistant Professor, Nursing Department, University of Peloponnese, Sparta, Greece \\ $R N$, MSc, General Hospital of Korinthos, Korinthos, Greece \\ Major RN, PhD, Technological Institution of Larisa, Nursing Department, Larisa, Greece \\ *Corresponding authorE-mail: zygas@uop.gr; zygas@spa.forthnet.gr
}

\begin{abstract}
Introduction: When designing new hospital construction or refurbishment can be adopted green practices both in design and in construction and operation.

Objective: To explore the ecological awareness and behavior of nursing staff in a dialysis unit.

Methods: This survey involved 90 Registered Nurses and Nurses' aides of General Hospitals in the Capital (Athens) and in province of Greece (Region of Peloponnese). These individuals were given an overall anonymous self-completed questionnaire.

Results: The most important finding is that $70.8 \%$ considered as mandatory an organized effort to protect the environment in their workplace. Nurses think that greater environmental awareness is obtained $37.1 \%$ by using guidelines, $23.6 \%$ with relative stimulation, and $20.2 \%$ with educational lectures, $10.1 \%$ using poster and $6.7 \%$ in view educational videos. Finally, the correlations of ecological awareness with demographic characteristics of the sample revealed that older nursing staff with more years of working experience knows about environmental management ( $p$ value $=0.012)$. At the same time, gender $(p$-value $=0,030)$ and educational level of the nursing staff plays an important role in the knowledge of it ( $\mathrm{p}$-value $=0,044)$.

Conclusions: To control costs and environmental pollution guidelines for saving energy and water and the use of environmentally friendly materials should be implemented. Thus, hospitals can become more competitive by reducing the amount of natural resources used.
\end{abstract}

Keywords: awareness, behavior, ecological, Green Hospitals, hemodialysis.

\section{Introduction}

According to International Council of Nurses the complexity and need for environmental protection and energy sources causes each professional group to actively participate in every effort to preserve the environment, aiming at saving resources [1]. Worldwide, hospitals and all health care facilities try to provide personalized, modern and high quality care, without burdening the natural environment. Global warming, climate change and the effort to adopt environmentally friendly habits are global issues from the late 20th century. In recent years, global organizations and legislative authorities at national and European level have been more sensitive to adopt rules for the protection of the environment, such as energy conservation, waste management, and safe management of pharmaceuticals.

Hospitals and all health organizations should be role models for their staff, patients, attendants and the general population. In these places more energy and water are consumed and much waste is produced compared to industries. Guidelines for saving energy and water and the use of environmentally friendly materials should be implemented to control costs and environmental pollution. In this paper an attempt is made to present good practice in Greece, and issues related to waste management in Dialysis Units are presented according to Greek and foreign countries' experience.

In countries such as the USA, knowledge how to build ecological healthcare organizations is developed in a satisfactory level. In addition, there are programs such as the "Green Code of Health and Hospitals for a Healthy Environment" that provide guidance and tools for the creation of green-offices services have supervision of hospital construction. The 
green service not only ensures the "health of buildings", but also contributes to the health of the local and global community. The backbone that a green office has is the control and proper operation of cooling and heating systems and energy saving matters $[2,3]$.

Mercury is a highly toxic metal that is harmful to the environment because of its long-term uncontrolled free disposal. Its deposition to the soil leads to its transfer in food chain. Even the smallest exposure to mercury, is associated with central nervous system damage, kidney and liver failure, abnormal reproductive system and fetal development, learning difficulties. The mercurial sphygmomanometers, containing 80-100g, is still used in European hospitals and private clinics. For this reason, a source of mercury, about 7-17 tons, is free into the environment and pose a health risk [4,5]. However, these devices should substituted by digital sphygmomanometers that do not contain mercury. The European Commission Directive 2007/51EC prohibited the use of this type of instrument in April 2009 [6, 7, and 8].

Many hospitals are reviewing the use of medical products made from PVC or vinyl because of potential harm to patients and the potential impacts on environmental health $[9,10]$. The use of flexible PVC medical devices exposes patients to the toxic substance (DEHP) during blood transfusion, the administration of fluids or parenteral nutrition with special bags, lines of hemodialysis or peritoneal dialysis, urine drainage bags, drains, oxygen masks, tracheal tubes, ambu, aspiration catheters or levin. When removed as waste PVC leads to dioxin exposure, a known human carcinogen substance that also causes abnormalities in the reproductive system and fetal development. We recommend using devices from silicon, polyethylene, polyurethane during interventions in male neonates, pregnant with male babies or teenage boys [11, 12, and 13].

The main source of dioxin in healthcare environments is the "traditional" burning of hospital waste. Products containing bleach and burned in blast, including medical devices and derivatives make dioxins [14].

Patients, staff and visitors at hospitals and clinics are at risk of developing asthma episodes. Given that hospitals are places of healing it is surprising that during patients' stay these individuals are exposed to health risks. The literature has shown that there are some factors in places providing health care that can cause asthma or asthma attacks. One of the main factors causing asthma is tobacco smoke. For this reason, smoking is banned in all public places since June of 2009. However, biological and chemical agents, such as chemicals for cleaning and disinfecting surfaces and instruments, chemicals for the construction of buildings and furniture production, latex gloves and medications are associated with asthma [15].

Stopping or reducing the use of chemical cleaning using mop and duster microfiber reduces the use of chemical cleaners in many places. These products are made from special fibers that trap dirt without the use of chemicals. Careful planning of cleanliness is important. The use of chemicals can be reduced by cleaning surfaces on a daily basis and not more often. The use of a milder cleaner for general cleaning on a regular basis and a strong cleaner only when necessary is possible to reduce exposure to risk factors. Prevention can help to reduce the chemicals. For example the use of specific carpet in the entrance of each clinic or room prevents the soil and reduces the frequency of cleaning. Replacement of latex gloves with latex-free gloves produced from nitrile rubber, neoprene or other material [11].

The construction and use of buildings in all sectors consume 3 billion tons of raw materials annually (40\% of rough stone, gravel, sand, and steel, $25 \%$ of virgin wood, $40 \%$ of its energy resources, $75 \%$ of PVC, $17 \%$ of freshwater flows) and causes significant waste (25-40\% of municipal solid waste and construction and demolition waste only), 50\% of CFCs, approximately $30 \%$ of production is $\mathrm{CO} 2$, and significant toxic emissions. Given this, the opportunities are important for improving the quality of the environment through eco-planning, design, construction, operation and maintenance practices. Improving the environment through green building practices is consistent with the recent voluntary agreement of the American Hospital Association in the United States and the Environmental Protection Agency to reduce waste and toxicity. The building design and construction practices can be configured for the protection of health $[16,17$, and 18].

Environmentally Friendly Hospitals: Two hospitals in Michigan are green, the Cancer Center of Santa Maria and the Boulder Community Hospital. The Cancer Center offers a rooftop garden that helps insulate the building and reduce water runoff. They also use the remaining steam from the heating system to melt snow sidewalks, reducing costs. The Boulder Community Hospital has painted the ceiling in white to reflect the heat of the summer and consequently reduces air conditioning demand. Regarding the cost of construction of these hospitals burdened the budget by $3 \%$. Hospital facilities that adopt environmentally friendly practices can save money help the environment and to minimize health risks from toxic substances [19, 20, and 21].

Ecological Hospitals: The prevention and treatment of disease in combination with health promotion has been the cornerstone of creating hospitals. Health is linked to the environment; it seems that any change in the environment has a direct impact on health [22]. The hospitals are a social microcosm using a variety of products, offer services, and generate a large number of waste that if not properly managed affects both health and the environment deleteriously. Health professionals are invited to defend public health in situations where water scarcity, air pollution and toxic products are flooding the environment and threaten public health. There is therefore an imperative need for hospitals to make their services safer, healthier and more environmentally friendly [2, 22]. A simple but essential step in this direction is the creation of "green" hospitals. The creation of green hospitals is feasible with strategies in respect to the development-creating sustainable buildings, the acquisition of environmental awareness and the use of environmentally 
friendly materials and consumables in the care of patients [22, 23, and 24]. Furthermore, climate change is one of the challenges of this century and has been recognized as a health priority [25].

The purpose of this study was to investigate the attitudes, perceptions and behaviors of nurses in Dialysis Unit regarding the existence of an ecological awareness, and their association with factors such as gender, age, educational profile, occupational status, working experience, and years of service

\section{Materials and methods}

\subsection{Sample}

The sample of the study was 90 Renal Nurses who worked in Dialysis Units in General hospitals in the Greek capital city and the region. The preconditions for the participation in the study were the following:

1) Adults (over 18 years)

2) Attaining at least a secondary educational level education.

3) The consent to participate in this study.

4) The questionnaires will be completed by the same people who participated in the survey.

5) The population under study was informed about the purpose and the privacy and anonymity of the process was guaranteed.

\subsection{Procedure}

The researcher provided the questionnaires with an envelope within which the person would deliver closed (in person) after completing the questionnaire in order to preserve confidentiality. Researchers were available to people who wanted to any pose questions.

\subsection{Questionnaire}

Individuals in the sample were given a total anonymous self-administered questionnaire designed for the purpose of the study that captures basic demographic characteristics and includes questions related to socio-demographic data (marital status, children, education level, employment status) and their identity (gender and age). Also, they were asked to answer questions related to years of service, professional experience and questions concerning the protection of the environment and in particular the system of environmental management; toxic management, water consumption, disposal of waste in Dialysis Unit. We also used some questions from the questionnaire "Go Green Dialysis" which EDTNA/ERCA used for pre-project survey, after written permission.

\subsection{Ethics}

This research has responded to the fundamental ethical principles governing the conduct of research. Specifically:

1) Complete discretion as to the information concerning the examinees was safeguarded.

2) Anonymity was guaranteed.

3) The results were used solely for the purposes of the research and only by this research group.

4) The reliability of the results ensured the accurate and complete description of the methods, the sample material and the general conditions of the survey.

\subsection{Data analysis}

A comparison of the responses of nursing staff between hospitals and demographic characteristics and questions on environmental protection and the development of ecological awareness was done. For these purposes the following statistical tests: the $\mathrm{x} 2$ test and the parametric comparison of more than 2 average price variance analysis in one direction (one-way ANOVA) were applied. The p-value based on two-tailed tests. The p-value with a value lower than 0.05 was considered as statistically significant. To perform the statistical analysis the software SPSS 18 was used. 


\section{Results}

Table 1 show that $19.1 \%$ of participants are male and the remaining $80.9 \%$ female. With regard to marital status, $25.6 \%$ of people are not married, $65.6 \%$ married, and $7.8 \%$ and $1.0 \%$ are divorced or widowed, respectively. $74.4 \%$ are Technological institution graduates, $4.4 \%$ are graduates of higher education (universities) and $14.4 \%$ secondary education. $6.8 \%$ has an additional postgraduate diploma qualification, while none has a doctorate. Referring to the nationality, the whole sample is Greek. $10.7 \%$ are located in Argolis, 27.4\% in Athens, $14.3 \%$ in Kalamata, $10.7 \%$ in Korinthos, $15.5 \%$ in Tripoli, $16.7 \%$ in Sparta and the remaining 4.8\% in Molai. Regarding the professional status, $7.8 \%$ of participants are head nurses. These descriptive statistics are presented in detail in Table 1.

Table 1: Demographic characteristics of the sample

\begin{tabular}{|c|c|c|}
\hline Demographics & $\mathrm{n}$ & $(\%)$ \\
\hline \multicolumn{3}{|l|}{ Sex } \\
\hline Woman & 72 & 80.9 \\
\hline Man & 17 & 19.1 \\
\hline \multicolumn{3}{|l|}{ Marital status } \\
\hline Single & 23 & 25.6 \\
\hline Married & 59 & 65.6 \\
\hline Divorced & 7 & 7.8 \\
\hline Widowed & 1 & 1.0 \\
\hline \multicolumn{3}{|l|}{ Children } \\
\hline No & 11 & 22.9 \\
\hline Yes & 37 & 77.1 \\
\hline \multicolumn{3}{|l|}{ Educational level } \\
\hline Technological institution & 67 & 74.4 \\
\hline University & 4 & 4.4 \\
\hline 2 year of training & 13 & 14.4 \\
\hline Master & 6 & 6.8 \\
\hline $\mathrm{PhD}$ & 0 & 0 \\
\hline \multicolumn{3}{|l|}{ Occupational profile } \\
\hline \multicolumn{3}{|l|}{ Hospital } \\
\hline Argolida & 9 & 10.7 \\
\hline Athens & 23 & 27.4 \\
\hline Kalamata & 12 & 14.3 \\
\hline Korinthos & 9 & 10.7 \\
\hline Tripolis & 13 & 15.5 \\
\hline Sparta & 14 & 16.7 \\
\hline Molai & 4 & 4.8 \\
\hline \multicolumn{3}{|l|}{ Occupational status } \\
\hline Public servant & 77 & 89.5 \\
\hline Contract staff & 9 & 10.5 \\
\hline \multicolumn{3}{|l|}{ Position } \\
\hline Head nurse & 7 & 7.8 \\
\hline Nurse & 82 & 92.2 \\
\hline
\end{tabular}

The average age of nurses was 38.4 years with a minimum age of 24 years and maximum of 49 years. The variable of age appeared to follow a normal distribution (symmetrical). Still, the $48(53.3 \%)$ of participants in the study had an average of 2 children. Finally, mean time of working experience was 13.5 years ranging from 0 to 29 years.

In Table 2 it is observed that $81.7 \%$ of respondents indicated that the nursing staff of Dialysis Unit can help protect the environment. According to the responses of nurses, $35.2 \%$ said that they believed that the volume of hospital waste could be limited, $31.8 \%$ believe that electricity consumption could be limited as well as water consumption $20.5 \%$ said that water consumption. The $37.1 \%$ of the respondents believe that their colleagues may be influenced to gain increased environmental awareness using guidelines using $20.2 \%$ educational lectures, $10.1 \%$ using posters and $6.7 \%$ with view educational videos, $23.6 \%$ with relative motivation. Still, $70.8 \%$ considered mandatory the support of an organized effort to protect the environment in their workplace, while $28.1 \%$ would support it if they had free time. 
Table 2: Attitudes, perceptions and behaviors of nurses regarding the protection of the environment and the motivation for development of ecological consciousness.

\begin{tabular}{|c|c|c|}
\hline Questions & $\mathrm{N}$ & $(\%)$ \\
\hline \multicolumn{3}{|c|}{ Do you think the Nursing Staff in Dialysis Units can help protect the environment? } \\
\hline No & 2 & 2.3 \\
\hline Yes & 71 & 81.7 \\
\hline Maybe & 14 & 16.1 \\
\hline \multicolumn{3}{|c|}{ In your opinion which of the following has a greater potential of reducing? } \\
\hline Water consumption & 18 & 20.5 \\
\hline Electricity power consumption & 28 & 31.8 \\
\hline Hospital waste & 31 & 35.2 \\
\hline Gas or oil consumption & 11 & 12.5 \\
\hline \multicolumn{3}{|c|}{ How do you think you can influence your colleagues to gain increased ecological awareness? } \\
\hline Posters & 9 & 10.1 \\
\hline Training video & 6 & 6.7 \\
\hline Speeches & 18 & 20.2 \\
\hline Guidelines & 33 & 37.1 \\
\hline Motivation & 21 & 23.6 \\
\hline Other & 2 & 2.3 \\
\hline \multicolumn{3}{|c|}{ Would you support an organized effort to protect the environment in your workplace? } \\
\hline Yes, I think it compulsive & 63 & 70.8 \\
\hline Yes, if I had free time & 25 & 28.1 \\
\hline No, I would not support it & 1 & 1.1 \\
\hline
\end{tabular}

About environmental management, 55.8\% of the sample responded that they have knowledge about the existence of a relevant law for the protection of the environment. The $43.1 \%$ of nurses said that "maybe" the hospital is implementing a program of environmental management. $51.1 \%$ responded that the hospital has an employee responsible for environmental management of hospital waste, energy, pollution, health and safety. $40.5 \%$ of the sample responded that they don't know what departments or individual services of Hospital consume hazardous or toxic agents. Also, according to $70.8 \%$ of the nursing staff personal protective equipment that are required for the handling of hazardous or toxic agents are readily available to staff.

There is a statistically significant correlation between sex and existence of place of incineration or landfill $(x 2=8.665$, $\mathrm{p}$-value $=0.013) .23 .5 \%$ of men are not sure if medical instruments with mercury are used in the unit $(\mathrm{x} 2=7.002, \mathrm{p}-$ value $=0.030$ ). $66.7 \%$ with two year of education are found to be positive that there is a system of environmental management of the waste of their unit (Fisher's exact test p-value=0,044). Age and working experience are also to have statistically significant correlation with characteristics of waste management in the Dialysis Unit as it shown in Table 3.

Table 3: Table of correlation between gender and education and questions about power management, toxic agents, water management and liquid waste management

Question $\quad$ Men $\begin{gathered}\operatorname{sex~n(\% )} \text { total } \\ \text { women }\end{gathered}$

Are unit waste transferred in places of landfill or incineration?

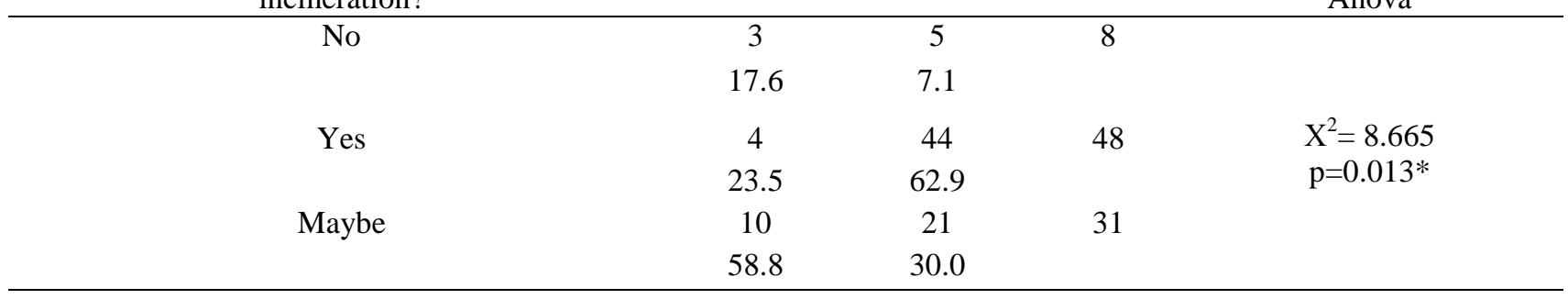

Toxic agents

Medical instruments with mercury

$\begin{array}{ccccc}\text { No } & 7 & 35 & 42 & \\ \text { Yes } & 41.2 & 49.3 & & \\ & 6 & 33 & 39 & \mathrm{X}^{2}=7.002 \\ \text { Maybe } & 35.3 & 46.5 & & \mathrm{p}=0.030^{*} \\ & 4 & 3 & 7 & \end{array}$




\begin{tabular}{|c|c|c|c|c|c|}
\hline \multirow{3}{*}{$\frac{\text { Use of environmental management system }}{\text { No }}$} & \multicolumn{2}{|c|}{$\begin{array}{c}\text { Educational Level } \\
\mathrm{n}(\%)\end{array}$} & \multirow[t]{2}{*}{ total } & \multirow{2}{*}{\multicolumn{2}{|c|}{ Fisher's exact }} \\
\hline & University & Two-year & & & \\
\hline & 18 & 0 & \multirow[t]{2}{*}{18} & \\
\hline \multirow{3}{*}{ Yes } & 23.7 & 0 & & \multirow{3}{*}{\multicolumn{2}{|c|}{$\mathrm{p}=0.032 *$}} \\
\hline & 24 & 8 & \multirow[t]{2}{*}{32} & & \\
\hline & 31.6 & 66.7 & & & \\
\hline \multirow[t]{2}{*}{ Maybe } & 34 & 4 & 38 & & \\
\hline & 44.7 & 33.3 & & & \\
\hline \multicolumn{6}{|c|}{ Use of environmental management system } \\
\hline Age (years: mean, SD) & No & Yes & Maybe & Total & Anova \\
\hline $\begin{array}{l}\text { Does your unit have a written } \\
\text { protocol for the supply of materials } \\
\text { environmentally friendly? }\end{array}$ & $39,66,16$ & $40,66,13$ & $35,36,50$ & $38,36,54$ & $\begin{array}{c}\text { F-test }=4,608 \\
p=0,013^{*}\end{array}$ \\
\hline $\begin{array}{l}\text { Does your unit have an integrated } \\
\text { system of waste management? }\end{array}$ & $40,65,53$ & 396,23 & $34,36,95$ & $38,36,54$ & $\begin{array}{c}\text { F-test }=5,729 \\
p=0,005^{*}\end{array}$ \\
\hline Working experience (years: mean, SD) & & & & & Anova \\
\hline $\begin{array}{l}\text { Does your unit have a written } \\
\text { protocol for the supply of materials } \\
\text { environmentally friendly? }\end{array}$ & $14,97,83$ & $15,59,33$ & $9,57,33$ & $13,48,01$ & $\begin{array}{c}\text { F-test }=3,683 \\
p=0,030^{*}\end{array}$ \\
\hline $\begin{array}{l}\text { Does your unit have an integrated } \\
\text { system of waste management? }\end{array}$ & $16,38,41$ & $13,67,61$ & $8,86,82$ & $13,48,01$ & $\begin{array}{c}\text { F-test }=4,206 \\
\mathrm{p}=0,019^{*}\end{array}$ \\
\hline $\begin{array}{c}\text { Is there any central location where } \\
\text { infectious waste are collected and } \\
\text { stored? }\end{array}$ & $5,54,27$ & $14,47,82$ & $4,01,41$ & $13,48,01$ & $\begin{array}{c}\text { F-test }=5,269 \\
p=0,007^{*}\end{array}$ \\
\hline $\begin{array}{l}\text { Is there a recycle unit for the produced } \\
\text { waste? }\end{array}$ & $6,86,05$ & $14,88,06$ & $12,46,91$ & $13,48,01$ & $\begin{array}{c}\text { F-test }=3,511 \\
\mathrm{p}=0,035^{*}\end{array}$ \\
\hline $\begin{array}{c}\text { Are unit waste transferred in places of } \\
\text { landfill or incineration? }\end{array}$ & $8,88,52$ & $15,97,03$ & $11,18,13$ & $13,48,01$ & $\begin{array}{c}\text { F-test }=4,744 \\
p=0,012 *\end{array}$ \\
\hline
\end{tabular}

* level of statistical significance $5 \%$

\section{Discussion}

Protecting the environment is extremely important for health, wellness and life itself. According to the International Council of Nurses (1986) the complexity and necessity of environmental protection causes each professional group to actively participate in every effort to preserve the environment [1]. Worldwide, hospitals and all health care facilities provide personalized, modern and high quality care. Global warming, climate change and the effort to adopt environmentally friendly habits are global issues from the late 20th century. In recent years, global organizations and legislative authorities at national and European level have been sensitized to adopt rules for the protection of the environment, such as energy conservation, waste management, and safe management of pharmaceuticals. Hospitals and all health service organizations should be role models for their staff, patients, attendants and the general population. In these areas the consumed energy, water, and waste produced are more than what the industries produce [26-28]. To control costs and environmental pollution guidelines for saving energy and water and the use of environmentally friendly materials should be implemented Thus, hospitals can become more competitive by reducing the amount of natural resources used.

In this survey 90 people constituted the total sample of the study in order to investigate ecological awareness and performance of nursing personnel in a dialysis unit. To achieve this aim, participants were given a comprehensive questionnaire which reflects the opinions, attitudes and beliefs related to environmental protection and the development of ecological awareness. The descriptive results from this study showed that the largest proportion of the sample believes that the Nursing Staff of Dialysis Unit can help protect the environment. In this direction, the volume of 
infectious waste seems to appear as the dominant power limitation. Moreover, the most popular way to motivate colleagues is to gain increased ecological awareness. An important finding is the fact that the vast majority feels obligatory to support any organized effort to protect the environment.

Finally, the correlations of ecological awareness with demographic characteristics of the sample revealed that older nursing staff with more years of working experience knows about environmental management. At the same time, gender and educational level of the nursing staff plays an important role in the knowledge of it. In conclusion, therefore, this study determined of the characteristics of nurses that affect the attitude toward the environment, and reflect the perceptions and attitudes about the development of ecological consciousness. So focusing on these elements, it is possible that this study can contribute substantially to raising Nurses in ecology. The ultimate goal is to reduce environmental pollution and creating "green" hospitals. In this way, hospitals will be friendlier to the environment, control costs and reduce waste of public money, and will work in favor of public health [1, 29-30].

A similar research study «Go Green in Dialysis» (Ecological approach Dialysis) prepared by EDTNA / ERCA (European Association of Nurses for Dialysis and Transplantation) and the company Fresenius Medical Care in 2010 [31]. That survey involved 872 people from 39 different countries and concluded also that:

Nurses in the Dialysis Unit can help to protect the environment. Low priority factor for nephrology units is the consumption of oil or natural gas. They also believed that the best way to improve colleagues'

Environmental consciousness is educational seminars. The present study also conclude that nurses believe that their colleagues could be influenced to gain increased environmental awareness using guidelines, with relative motivation, and with educational lectures, using posters and educational videos.

Energy saving saves money and helps hospitals to become competitive. The parts of the hospital that consume large amounts of energy must be recognized in order to investigate the possibility of reducing energy consumption. The recirculation of the air, the adjustment of temperature depending on the department and the improvement the insulation of the building can reduce hospitals heating and cooling needs [32]. The environmental management should include objectives, timetable and persons responsible for the adoption of recycling and responsible waste management. An environmental management system, however, requires the support and involvement of all levels of workers. Staff training, reporting and presentation of successes increase their enthusiasm and contribute to the success of the management system. Instructions should be written for handling, storage and disposal of dialysis unit waste.

The cost of a hospital for lighting can be reduced by replacing ordinary light bulbs with energy saving bulbs, reducing lighting sources, installing motion detectors and installing larger windows to use natural light. The solar collectors can reduce the energy or fuel used. Wind turbines and geothermal energy accumulators are potential sources of energy to run a hospital

\section{Conclusion}

When designing new hospital construction or refurbishment can be adopted green practices both in design and in construction and operation. Thus, can be used:

1) For heating: Solar batteries, thermostats temperature decline, reducing the room temperature at night, hot water collection tanks, small boiler in order to insulate the pipes, boilers and tanks.

2) For electricity: modern lighting elements, night lighting, motion detectors, appliances energy class A.

3) For air conditioning should estimate the parameters of each clinic, placed thermostats, insulated pipes, reducing the flow of air in empty rooms or workplaces, recirculation of cold air batteries for photovoltaic energy production, planting and placement of plants to reduce uptake of solar and wind blocking, positioning obscuration films on windows to reduce heat loss.

Nurses should and can adopt ecological attitude and behavior, both in the workplace and in the community. This is done with the following proposed ways: avoid any direct contact with mercury, information on mercury levels and implementation of international guidelines, fewer thermometers and sphygmomanometers, proper removal of those containing mercury according to international regulations, dental use of substances that do not contain mercury, use of materials, latex-free and PVC (floor, wall paints, carpets, roof lining, piping), using wood products without formaldehyde, chromium or arsenic, use materials manufactured without ozone depletion, recyclable metal and cement, training of staff, measurement of energy and water consumption, greenhouse gas emissions, waste, adopting recycling programs.

\section{References}

[1] International Council of Nurses, the Nurse's Role in Safeguarding the Human Environment. Position Statement, Geneva, 1996.

[2] J. Kreisberg, Energy, Sustainable Medicine and 21st Century Healthcare: Opportunities for the future? (Internet) 2005; Available online: http://www.cleanmed.org/2009/downloads/presentations/F7/Joel_Kreisberg.pdf. Accessed March 7, 2013. 
[3] T. Lent, Improving indoor air quality with the California 01350 specification. Healthy Building Network. (Internet) 2006; Available online: http://www.healthybuilding.net/healthcare/CHPS_1350_summary.pdf.Accessed March 23, 2013.

[4] A. Lind, E. Limberidi-Settimo, L Hammer, EU mercury phase out in measuring and control equipment, European Environmental Bureau, Brussels, 2009.

[5] NK. Markandu, F. Whitcher, A. Arnold, C. Carney, The Mercury sphygmomanometer should be abandoned before it is proscribed, Journal of Human Hypertension14 (2000):31-36.

[6] D. Mion, A.M.G. Pierrin, How accurate are sphygmomanometers? Journal of Hypertension 12(1998) $245-48$.

[7] KEMI-Swedish Chemical Inspectorate, Mercury-free blood pressure measurement equipment. Experiences in the Swedish healthcare sector, Sundbyberg, 2005.

[8] C. Floyd, B. Tarkowski, and Risks to Health and the Environment Related to the Use of Mercury Products: Final Report prepared for the European Commission, 2002, DG Enterprise by Risk \& Policy Analysts Limited.

[9] Greening Hospitals-Healthcare Without Harm Environmental Working Group - The Tides Center (Internet) 1998; Available online: www.ewg.org/pub/home/reports/greening/greening.pdf.Accessed March 23, 2013.

[10] S. Davis, 10 ways to reduce regulated medical waste in Health Care without Harm. (Internet) 2002; Available online: http://www.deq.state.id.us/multimedia_assistance/hospitals/hwhmedicalwastereduction.pdf. Accessed March $23,2013$.

[11] G. McCartney, P. Hanlon, What can health professionals contribute to the challenge of sustainability? Public Health 123(2009) 761-64.

[12] PVC Free Alternatives Materials, (Internet) 2002; Available from: www.healthybuilding.net/hindex.html. Accessed March 23, 2013.

[13] K. Ruzickova, M. Cobbing, T. Rossi Belazzi, Preventing harm from Phthalates, avoiding PVC in Hospitals. Healthcare without harm. (Internet) 2004; Available from: http://www.env-health.org/IMG/pdf/PVC_in_hospitals.pdf. Accessed March 23, 2013.

[14] HCWH. Instruments, Products, and Laboratory Chemicals Used in Hospitals That May Contain Mercury - Health Care without Harm. (Internet) 2002; Available online: www.noharm.org/library/docs/Going_Green_List_of_MercuryContaining_Items_i.pdf.Accessed March 7, 2013.

[15] P. Wilkinson, K.R. Smith, M. Davies, H. Adair, B.G. Armstrong, M. Barrett, N. Bruce, A. Haines, I, Hamilton, T. Oreszczyn, I. Ridley ,C. Tonne, Public health benefits of strategies to reduce greenhouse-gas emissions, Household energy374 (2009) 1917-1929.

[16] Health Care without Harm. Press Release: Government Panel Expresses "Serious Concern that Toxic chemical in Vinyl Medical Products May Harm Sick Infants. (Internet) 2000, Available from: http://en.calameo.com/read/0008740124bf1481d4997. Accessed March 17, 2013.

[17] J. Emmanuel, R. Stringer, A global inventory of alternative medical waste treatment technologies. (Internet) 2007; Available online: http://www.gefmedwaste.org/downloads/For\%20Proper\%20Disposal.pdf.Accessed March 17, 2013.

[18] D. Georgara, Hemocatharsis waste management in the Dialysis Unit of the General Hospital of Kyparrisia. Dialysis Living 2 (2011) 19-20.

[19] A. Reller, Greener Hospitals, Improving Environmental Performance. (Internet) 2008; Available online: http://agpi.cegep-stlaurent.qc.ca/archives/visez-vert/Reference110mai2007.pdf.Accessed April 20, 2013.

[20] W. Wang, Sustainable building development in China. (Internet) 2006; Available online: http://www.ectp.org/documentation/D2-42Wang.pdf. Accessed April 20, 2013.

[21] E. Hockridge, J. Longfield, Getting more sustainable food into London's hospitals. Sustain, London. (Internet) 2006; Available online: http://www.sustainweb.org/hospital_index.asp.Accessed April 20, 2013.

[22] Healthcare without harm. (Internet) 2008; Available online: http://www.noharm.org/us_canada/news_hcwh/2008/oct/hcwh2008-10-17.pdf Accessed April 20, 2013.

[23] K. Kümmerer, Significance of antibiotics in the environment. Journal of Antimicrobial Chemotherapy 52(2003) 5-7.

[24] K. Kümmerer, M. Scherrer, P. Hubner, L. Metz, FD Daschner. (Eds.), Environmental Management for Hospitals, Pharmacies and Practical Surgeries. Kenzingen, 2001.

[25] S. Tong, P. Mather, G. Fitzgerald, D. Mc Rae, K. Verral, D. Walker, Assessing the Vulnerability of Eco-Environmental Health to Climate Change. Public Health (Internet) 2010; Available online: http://www.mdpi.com/1660-4601/7/2/546/pdf.Accessed April 20, 2013.

[26] J. Agar, Reusing Dialysis Wastewater: the elephant in the room, American Journal of Kidney Diseases 52(2008) 10-12.

[27] F. Tarrass, M. Benjelloun, and O. Benjelloun, Recycling wastewater after hemodialysis: an environmental analysis for alternative water sources in arid regions, American Journal of Kidney Diseases 52(2008)154-158.

[28] Environmentally Responsible Health Care. Nurses can make a difference. (Internet) 2002; Available from: www.nihe.org. Accessed April 20, 2013.

[29] Nurses can make a difference: The Nightingale Institute for Health and the Environment (Internet) 2002; Available online: http://www.nursezone.com/Nursing-News-Events/more-features/Web-Project-Enlightens-Nurses-aboutEnvironmentallssues_22022.aspx.Accessed April 20, 2013.

[30] A. Connor, F. Mortimer, T. Charles, Clinical Transformation: The Key to Green Nephrology, Nephron Clinical Practice 116(2010) 200-206.

[31] EDTNA/ERCA newsletter (Internet) 2010; Available online: http://www.edtnaerca.org/pdf/education/newsletter/2010/News2_GRE.pdf.Accessed April 2, 2013.

[32] National Primary Federal Energy Management Program, US Environmental Protection Agency. (Internet) 2002; Available online: www.eren.doe.gov/femp/techassist/savenergyprog.html.Accessed April 20, 2013. 